\title{
Analise da representação da figura do cientista em filmes de ficção cientifica
}

\author{
Analysis of the scientist figure representation in scientific fiction films
}

Amanda Berk Queiroz ${ }^{1}$

Marcelo Borges Rocha

\section{Resumo}

Entendendo o potencial que o cinema tem para apresentar informações, inclusive científicas, para o público em geral, torna-se importante entender como a figura do cientista vem sendo representada nestas obras. Assim, neste estudo foram selecionados 14 filmes de ficção científica com o objetivo de investigar as representações de cientista nas atividades cientificas. A análise do material foi pautada na análise fílmica proposta por Vanoye e Goliot-Leté, associada à análise de conteúdo categorial temática de Bardin. As categorias foram elaboradas a priori e a posteriori da observação dos filmes. Foi possível constatar a predominância da figura do cientista heróiaventureiro com habilidades para solucionar problemas de caráter cientifico e que se arrisca em favor da humanidade. Destaca-se que representações como esta e, as demais encontradas no estudo, podem reforçar padrões de cientistas que permeiam o imaginário da população. Considera-se assim, que as reflexões apresentadas tornam-se relevantes no sentido de gerar possíveis desdobramentos para outras pesquisas que contribuam para problematizar a visão de cientista na produção do conhecimento cientifico.

Palavras chave: ficção científica; cinema; cientista.

\section{Abstract}

Understanding the potential that cinema has to present information, including scientific, to the general public, it is important to understand how the figure of the scientist has been represented in these movies. Thus, in this study 14 science fiction films were selected in order to investigate the representations of scientist in scientific activities. The analysis of the material was based on the analysis proposed by Vanoye and Goliot-Leté, associated with the thematic categorical analysis according to Bardin. The categories were elaborated a priori and a posteriori of watching the films. It was possible to verify the predominance of the figure of the heroadventurer scientist with abilities to solve problems of a scientific character and who risks himself in favor of humanity. It is noteworthy that representations like this one, and the others found in the study, can reinforce patterns of scientists that permeate the population's imagination. It is considered, therefore, that the reflections presented become relevant in the sense of generating possible consequences for other research that contribute to problematize the scientist's vision in the production of scientific knowledge.

Keywords: Science fiction; cinema; scientist.

\footnotetext{
${ }^{1}$ Centro Federal de Educação Tecnológica Celso Suckow da Fonseca | berk.amanda@yahoo.com.br

${ }^{2}$ Centro Federal de Educação Tecnológica Celso Suckow da Fonseca | rochamarcelo36@yahoo.com.br
} 


\section{Introdução}

Um dos aspectos mais discutidos em relação às representações que os sujeitos fazem da ciência é a imagem do cientista. A partir da imagem do cientista, o indivíduo pode elaborar uma concepção do que consiste o processo de investigação científica. Diversos trabalhos abordam como essa imagem é retratada na sociedade. Existe um estereótipo predominante, como discorrem Tomazi et al. (2009), representado geralmente por um indivíduo masculino, de cor branca, pouco sociável, vestindo jaleco e óculos, cabelos despenteados e, que realiza suas atividades em laboratórios utilizando pipetas, tubos de ensaio e microscópios.

Kosminsky e Giordan (2002) apontam que existem vários tipos de imagem da ciência e, consequentemente de cientista. Os autores sinalizam que cientista é "a pessoa que cultiva particularmente alguma ciência; especialista numa ciência, ou em ciências" (KOSMINSKY; GIORDAN, 2002, p. 11). Desta maneira, não há atribuição ou característica física específica para o exercício da atividade científica. Além do que, existem diversas áreas que abrangem as ciências, como por exemplo, as médicas, sociais, físicas, tecnológicas, ambientais, entre outras, que irão incorporar exigências próprias para a execução de suas atividades.

Um estereótipo comum de cientista, seria, portanto, no mínimo negligente com algum aspecto particular inerente de tantos âmbitos possíveis. Contudo, a representação que torna obrigatória uma série de elementos quando há alguma referência quanto à atividade científica é bem marcante. A manifestação de indivíduos acerca de cientistas geralmente inclui ao menos um dos elementos conhecidos como parte do universo científico. Apesar de na realidade muitos desses componentes não fazerem parte, ou até mesmo, não serem necessários para a prática científica, há uma reprodução de sua inclusão quando é solicitada a representação do cientista.

Corroborando com esta discussão, Albuquerque (2017) percebe distorções na percepção de alunos do ensino médio, tanto na imagem da ciência quanto do cientista. $O$ autor indica que esse dado sugere que há uma necessidade de adoção de novas metodologias para a discussão sobre ciência em sala de aula. Breunig, Amaral e Goldschmidt (2019), em estudo com alunos do ensino médio, também observaram muitas concepções errôneas sobre cientistas e ciência. Nesse sentido, Santos, Pasini e Rudek (2015) argumentam que uma estratégia que apresenta potencial para a discussão e problematização das representações sobre ciência e do cientista é a utilização de filmes comerciais para suscitar debates e reflexões. Albuquerque (2017) salienta que a utilização histórico-crítica de filmes comerciais, através de uma abordagem histórico-filosófica da ciência, pode colaborar para que o docente contextualize os conteúdos e discuta aspectos relacionados ao conhecimento científico.

Santos e Scheid (2011) verificaram, em seu estudo, a importância do uso do cinema para discutir as percepções de estudantes do ensino médio acerca da ciência e do cientista. Após solicitar que os alunos observassem esses aspectos durante a exibição dos filmes, constataram, que de modo geral, a visão é mitificada e com orientações positivistas, ou seja, a fala dos estudantes acabam por reforçar o estereótipo de cientista e do fazer ciência. Assim, as autoras sugerem que sejam realizadas mais atividades no sentido de aproximar os estudantes das questões inerentes da ciência, entendendo que o cinema configura-se como importante recurso para estas discussões.

Além de pesquisas com estudantes de ensino médio, percebe-se distorções conceituais acerca do papel do cientista também com licenciandos do curso de ciências biológicas 
(SCHEID, FERRARI e DELIZOICOV, 2016). Os autores discutem os impactos que essas visões podem trazer nas práticas pedagógicas destes futuros professores. Assim, pontuam que possivelmente durante a graduação há uma ausência de discussões epistemológicas que esclareçam os pontos equivocados sobre a construção do conhecimento científico e o papel do cientista.

Entendendo esta realidade e percebendo o potencial do cinema, diante da linguagem narrativa típica, a forma que retratam os personagens e pelas atitudes que expressam emoções, levantamos o seguinte questionamento: que representações de cientista são veiculadas em filmes, em especial os de ficção científica?

O gênero de ficção cientifica possui uma série de características peculiares, que se destacam pela intenção de contribuir para a formação do imaginário científico do indivíduo. Além disso, estes filmes podem impulsionar os espectadores a pesquisar e buscar novos caminhos no entendimento dos processos internos da Ciência (QUEIROZ, 2019). Assim, justifica-se a escolha deste gênero para as análises.

Diante do exposto, o presente estudo teve como objetivo analisar as representações de cientistas em filmes de ficção cientifica, entendendo o potencial destes recursos na divulgação de informações sobre temas relacionados à ciência.

\section{Metodologia}

Diante da grande quantidade e variedade de filmes de ficção cientifica, foram selecionados 14 filmes de diferentes décadas, com grande inserção no cenário mundial e que suscitassem questionamentos acerca dos mecanismos internos da ciência, como por exemplo, a representação da figura do cientista (Quadro 1).

Quadro 1. Filmes de fiç̧ão cientifica analisados

\begin{tabular}{|c|l|c|}
\hline Código & Título do filme & Ano de produção \\
\hline FIC01 & 2001: Uma Odisseia no Espaço & 1968 \\
\hline FIC02 & BladeRunner & 1982 \\
\hline FIC03 & De Volta Para o Futuro & 1985 \\
\hline FIC04 & Jurassic Park & 1993 \\
\hline FIC05 & A Experiência & 1995 \\
\hline FIC06 & Contato & 1997 \\
\hline FIC07 & Velocidade do Vento & 2003 \\
\hline FIC08 & Efeito Borboleta & 2004 \\
\hline FIC09 & O Dia Depois de Amanhã & 2004 \\
\hline FIC10 & A Ilha & 2005 \\
\hline FIC11 & O Quarteto Fantástico & 2005 \\
\hline FIC12 & 2012 & 2009 \\
\hline FIC13 & Avatar & 2009 \\
\hline FIC14 & Wolverine & 2013 \\
\hline
\end{tabular}

A análise dos filmes foi realizada com o suporte dos pressupostos da Análise de Conteúdo (Bardin, 2011) e da Análise Fílmica (Vanoye e Goliot-Lété, 2006). A primeira contribuiu no sentido de possibilitar a criação de categorias de análise. Segundo Fioresi e Cunha (2016) este tipo de análise representa um modo de construção de atitudes, opiniões, indicadores, valores e comparações de conceitos e comunidades pertinentes para a 
delineação de panoramas e modelos diversos. Assim, o objetivo de identificar as representações de cientista tornou-se possível e gerou reflexões críticas.

De acordo com Silva et al. (2005), a elaboração das categorias de análise segue três modelos: o aberto, onde as categorias não são definidas a priori, o modelo fechado, onde o pesquisador já possui categorias previamente definidas baseadas no aporte teórico, e o modelo misto, onde o pesquisador já tem categorias definidas porém acrescenta outros critérios a partir da análise dos dados. No presente estudo, seguiu-se o modelo misto, visto que traz as categorias consideradas relevantes e desenvolvidas por autores de referência da área de análise do cinema para discutir Natureza da Ciência (Oliveira, 2006) e acrescenta outras a partir da leitura dos filmes.

As categorias criadas acerca das representações de cientista foram: Cientista heróiaventureiro, neste caso o cientista possui grande habilidade de resolver enigmas e encontrar solução para questões científicas complexas. Não receia em se arriscar e daria a própria vida pela ciência; Cientista diabólico, nesta categoria o cientista é retratado como vilão, com má índole e que conduz sua pesquisa para fins que prejudicarão outras pessoas. Tem a pretensão de ultrapassar os limites humanos; Cientista professor, esse tipo de cientista é ingênuo, inteligente e capacitado acima da média. Geralmente tem boas intenções com suas pesquisas, contudo é manipulado e enganado por alguém que toma o controle e deturpa seus objetivos; Cientista idealista é aquele visto como o salvador da humanidade. Geralmente dedica-se a encontrar uma maneira, através da ciência, para resolver os problemas enfrentados pela humanidade. Revela-se como um indivíduo sonhador que planeja sociedades utópicas. Por fim a categoria Cientista inventor com perfil extremamente inteligente, considerado genial. Apresenta ideias científicas inovadoras e consegue desenvolver meios de concretizá-las de maneira que ninguém mais parece ser capaz. Apresenta, contudo, problemas emocionais, como certos desequilíbrios que o tornam uma figura instável.

Para a elaboração destas categorias, foram utilizados os pressupostos da Análise Fílmica. Vanoye e Goliot-Lété (2006) exemplificam os mecanismos de análise, apontando uma série de elementos a serem observados pelo pesquisador. Dentre estes, citam o cenário, a direção, os personagens, o ritmo de cena e o plano de sequência dos filmes. Cada elemento é identificado e descrito detalhadamente no que é considerada a primeira fase da análise: a descrição. Esta etapa para Vanoye e Goliot-Lété (2006) consiste na decomposição do filme em elementos constitutivos. Esse processo de separação e seleção é explicitado pelos autores como um momento de percepção de fragmentos, que não seriam facilmente percebidos isoladamente a olho nu e, portanto, o papel do analista ao identificar esses elementos torna-se fundamental.

Os autores indicam que se faça anotações enquanto o filme está sendo assistido, e de preferência que sejam feitas pausas e repetições de trechos específicos. A possibilidade desse acesso ao filme de forma irrestrita para que seja possível a realização dessas observações minuciosas é fundamental para não comprometer a qualidade da análise. Todas estas recomendações foram seguidas no processo de análise dos 14 filmes de ficção que compõem o corpus desta pesquisa.

Assim a Análise de Conteúdo articulada à Análise Fílmica, permitiu ressaltar a temática do filme e discutir de forma contextualizada interpretações, valores e conceitos atrelados ao que está sendo apresentado sobre representação de cientista. 


\section{Resultados e discussão}

Em relação às categorias criadas para representar a figura do cientista nos filmes analisados, foi possível observar que houve um predomínio do Cientista herói-aventureiro com seis filmes, seguido pela imagem do Cientista professor com três, Cientista diabólico e Cientista idealista com dois cada e, por fim Cientista inventor com uma ocorrência.

Em nossas análises identificamos que os filmes FIC 01, FIC 04, FIC 06, FIC 07, FIC 11 e FIC 13 se enquadraram na categoria cientista herói-aventureiro. Barca (2005) define que, a partir da década de 1980, ocorreu o início de uma fase pioneira por Indiana Jones, em que o cientista assume um papel mais simpático e ousado nas telas do cinema. O personagem é um cientista que utiliza seus conhecimentos para desvendar mistérios e salvar o mundo.

Essa categoria é fundamental para desmistificar o modelo de cientista preso ao estereótipo do laboratório, de jaleco e óculos. Em relação à aparência, os filmes pertencentes a essa categoria apresentam uma variedade de representações, desde vestimentas ao corte de cabelo e acessórios utilizados pelos cientistas. Um aspecto que pode ser observado é que nenhum dos personagens dessa categoria utiliza óculos, um dos adereços mais observados e apontados no estereótipo de cientista indicado pelo senso comum (TOMAZl et al., 2009).

A aproximação da ciência como uma atividade profissional que inclui pessoas comuns e de todos os tipos, é uma desconstrução importante para a percepção popular da ciência. 0 distanciamento e o protótipo de que a ciência é exercida por indivíduos privilegiados ou idealizados é prejudicial tanto para a concepção de ciência como para o ingresso de grande parte dos indivíduos no campo científico.

Em Jurassic Park, o protagonismo científico é dos pesquisadores Ellie Sattler e Alan Grant. Ambos, desde o início do filme, são apresentados de maneira despojada, atuando no campo em um acampamento, comandando e realizando escavações paleontológicas. 0 ambiente científico representado nesse contexto, por si só, já desconstrói o modelo tradicional de atividade científica, onde há a necessidade de laboratórios esterilizados, um ambiente impecável contendo equipamentos e aparatos delicados como vidrarias e microscópios.

Essa divulgação de espaços alternativos de pesquisa é um aspecto interessante trazido no filme Jurassic Park, onde em algumas cenas os pesquisadores estão no campo, realizando escavações de um fóssil encontrado e utilizam instrumentos como escovas, pincéis, martelos, entre outras ferramentas rudimentares para revelar os ossos do exemplar. Dependendo da área científica, como é o caso da Paleontologia, só é possível o desenvolvimento da pesquisa a partir da realização da etapa do campo.

Interessante destacar que segundo Latour (2012), os trabalhadores das áreas de pesquisa em ciências que ocupam os laboratórios representam apenas um quarto da mão de obra relacionada à pesquisa e desenvolvimento de elementos tecnocientíficos. Os outros três quartos são compostos por cientistas que ocupam outros contextos de pesquisa.

Acerca da aparência dos cientistas em Jurassic Park, percebemos a postura mais aventureira dos personagens, onde tanto o Dr. Grant como a Dra. Sattler não utilizam jaleco, mas sim calças, ela bermuda e camisas. O Dr. Grant inclusive utiliza em diversas cenas óculos escuros, um lenço vermelho e chapéu, que conferem um ar mais descontraído.

As personalidades dos personagens também condizem com suas aparências, ambos demonstrando-se como indivíduos mais despojados, desprovidos de muitas formalidades. 
O caráter curioso e investigativo é manifestado pelos cientistas em diversos trechos do filme, assim como a audácia e a coragem face aos desafios a serem enfrentados no decorrer das cenas.

Esse perfil mais destemido, apresentado pelos cientistas pertencentes a essa categoria, contradiz o estereótipo do senso comum atrelado aos cientistas tradicionais. Os cientistas do senso comum pertencem à classe dos intelectuais, que geralmente não relacionam-se muito com atividades de risco e situações de aventura e perigo. A mudança deste paradigma, a partir do exposto por Barca (2005), inclui uma série de filmes e personagens científicos com essas características mais arrojadas e ousadas.

O cientista nesses filmes passa a ser representado não mais como aquele indivíduo intelectual, franzino, indefeso e amedrontado, como acreditava-se e associava-se à imagem do que seria também um "nerd" e que deveria ser salvo ou protegido por algum herói, ou então seria ameaçado e controlado por algum vilão. Agora, os personagens cientistas seriam os próprios heróis aventureiros, investigativos e capazes de elaborar planos e soluções por si mesmo e inclusive pelos outros personagens e até a humanidade. A combinação da inteligência científica com a bravura configurou um marco para a mudança do imaginário científico popular (QUEIROZ, 2019).

Os personagens dessa categoria também revelam a capacidade de assumir novas funções além da teoria, onde anteriormente restringiam-se mais ao campo das ideias, elaborando hipóteses e executando alguns experimentos em laboratório, mas com esse posicionamento heroico-aventureiro, os cientistas desbravam horizontes novos, enfrentando as consequências negativas do rumo de suas próprias pesquisas ou efeitos colaterais surgidos por pesquisas de outros, ou até mesmo por mudanças ocasionadas no planeta.

Nesse sentido, o cientista não somente orienta ou oferece meios para que outro indivíduo solucione aquela determinada questão iminente, mas sim voluntaria-se para testar e comprovar sua hipótese ou então enfrenta por si mesmo o dano causado por um desvio no curso da ciência, aplicando dessa forma o seu conhecimento em situações práticas de alto risco e desafio.

No âmbito de se oferecer para uma missão científica imprevisível e arriscada, podemos citar a personagem Dra. Eleonor Arroway de Contato. Na empreitada de viagem no espaço para a estrela Vega, em uma máquina onde as plantas e diretrizes para sua construção foram enviadas por alienígenas, a cientista decide candidatar-se para a execução da missão de viajar para a estrela e estabelecer um possível contato com os alienígenas.

Inclusive demonstra uma certa ansiedade, angústia, nervosismo e até apego, diante do desejo de realizar esse feito, no momento em que é desvendada a planta da máquina por completo e the é informado que os governantes irão construí-la. Em diálogo com seu amigo teólogo, prontamente manifesta seu interesse em saber quem seria eleito para a função.

Ellie: Me conta.

Amigo: Vão construí-la.

Ellie: Quem vai poder ir?

Amigo: Será algo internacional, para dividir custos e riscos da construção.

Ellie: Mas quem vai?

Amigo: É complicado, Ellie. Formaram um grupo internacional de candidatos.

Ellie: (abaixa a cabeça em tom de desaprovação e reclamação, resmungando um pouco.) 
Amigo: A descoberta foi sua. Eles entendem isso. Você está no topo de uma seleta e pequena lista, mas eles vão criar um comitê formal de seleção. É formado por acadêmicos, teólogos, cientistas, filósofos.

Dra. Arroway, por ter sido a responsável pela descoberta da mensagem enviada pelos extraterrestres, ter informado às autoridades e ao mundo sobre sua existência, ter se empenhado e colaborado para decifrá-la, e possuir grande interesse e motivação nessa pesquisa desde sua infância, manifestou o desejo de desempenhar a tarefa de viajar no espaço e estabelecer contato com os alienígenas, inclusive considerando ter direito de realizar essa ação, diante de toda sua participação e contribuição. Sendo assim, demonstra ter um espírito aventureiro, como ela mesma define em outro trecho do filme.

Os filmes Velocidade do Vento e 2001: Uma Odisseia no Espaço apresentam semelhanças no heroísmo de seus personagens. Tanto o Dr. Timothy Briggs de Velocidade do Vento, quanto Dr. Dave Bowman de 2001, se arriscam diretamente em suas missões, a fim de solucionar as problemáticas científicas existentes.

Dr. Briggs se lança de um avião no vértice de uma espécie de furacão, em um vento de altíssima velocidade, repleto de raios e descargas elétricas, a fim de manusear a máquina que foi depositada no interior do redemoinho com o objetivo de neutralizar a tempestade. O risco físico sofrido naquele momento e a iminência da própria morte não impedem o cientista de realizar tal feito heroico.

A maneira como o personagem assume a responsabilidade para resolver o problema e a disposição em se arremessar daquela forma, mantendo uma postura confiante e contradizendo inclusive as recomendações de outros colegas cientistas, que não apoiaram sua atitude de alto risco, revela o perfil heroico-aventureiro do personagem. Em uma cena do filme, o cientista Dr. Timothy Briggs aparece paramentado em trajes protetores, enquanto está prestes a se arremessar de um avião, em uma área de alto risco de raios e turbulências, com o equipamento que controlará a tempestade de vento. A imagem de cientista representada pelo personagem é diferente do estereótipo difundido e demonstra um traço aventureiro marcante.

Em 2001: Uma Odisseia no Espaço, Dr. Bowman encontra-se em uma situação profundamente delicada, durante uma viagem em direção a Júpiter, diante de uma frequência alienígena a ser averiguada, o computador de sua nave, adquirindo emoções humanas e raciocínio próprio, rebela-se contra a equipe e decide iniciar ações de sabotagem com a mesma. O cientista, então, perde sua comunicação com a central, assim como restringe-se à operação manual de portas e equipamentos, uma vez que todo o sistema é comandado por HAL 9000.

Dentro desse cenário, Dr. Bowman se vê à mercê da própria sorte e habilidade técnica para salvar sua própria vida e cumprir sua missão. Desse modo, inicia uma tentativa em aventurar-se desde o retorno à nave base, em uma tentativa de resgatar um companheiro à deriva no espaço por uma sabotagem de HAL, até o desligamento do sistema, inativando o mesmo para que a viagem mantivesse seu curso. Em cenas tensas, em que HAL tenta afetar o cientista psicologicamente, o mesmo permanece em seu objetivo, conseguindo alcançálo. A luta travada pelo cientista e a demonstração de sua capacidade para lidar diante de uma situação de crise extrema, revelam seu perfil heroico-aventureiro.

Em Avatar e Quarteto Fantástico, os cientistas despontam como integrantes da categoria heroico-aventureiros, engajando-se inclusive em batalhas e confrontos bélicos diretos defendendo suas causas. Não é comum cientistas assumirem essa função de 
guerreiros, porém, esses personagens, devido a suas habilidades e poderes especiais adquiridos, como é o caso de Quarteto Fantástico ou a necessidade de situações de crise, em que os objetos de sua pesquisa correm risco de destruição, cenário de Avatar, os cientistas incorporam essa identidade, enfrentando lutas e confrontos diretos.

O cientista Dr. Reed Richards cria a teoria de que a exposição a uma nuvem cósmica altamente energizada combinada a ventos solares pode ter contribuído com a evolução da vida no planeta Terra. O cientista descobre uma nova nuvem de semelhantes características que passará pela órbita da Terra e sugere que, realizando um estudo no espaço no momento em que a nuvem estiver passando, será possível ampliar os conhecimentos sobre os genes humanos, desenvolvendo a cura para diversas doenças, prolongar a vida humana, entre outros avanços científicos. Contudo, durante a viagem espacial, ocorre um imprevisto, que expõe os cientistas Susan Storm e Reed Richards a um acidente radioativo, transformando sua composição molecular e fazendo com que os mesmos adquirissem superpoderes.

Para deter o vilão Victor Von Doom, empresário financiador da pesquisa que também foi submetido à transformação durante a viagem, os cientistas Reed e Susan compõem o Quarteto Fantástico, junto com o irmão dela Johnny e o amigo dele Ben. Apesar de não possuírem treinamento de luta ou qualquer tipo de preparo para funções de batalha, os cientistas encaram essa situação para evitar que o vilão cause estragos e domine a cidade.

O plano de Reed elaborado para derrotar Victor aproveita os poderes dos quatro personagens e utiliza conceitos científicos quando, ao saber que a transformação de Victor o fez ter uma composição metálica em seu organismo, decide aquecer o vilão a uma temperatura altíssima utilizando o poder de fogo de Johnny, enquanto o campo magnético de Susan faz um escudo protetor, evitando que o vilão escape, e Ben jorrando por fim um jato forte de água gelada no vilão, provocando um choque térmico que o petrifica. Reed inclusive cita na cena, como se fosse uma questão de química, em que indaga ao vilão "O que acontece quando se esfria rapidamente metal quente?", demonstrando como uma espécie de experimento o que ocorre com Victor.

No caso de Avatar, a Dra. Grace quando constata a iminente devastação de Pandora, o planeta tão belo e rico ao qual havia se dedicado nos últimos anos a investigar em sua pesquisa, não hesita em enfrentar o comando militar decidido a explorar os recursos disponíveis no local. Os militares encerram o prazo disponibilizado à Dra. Grace de realizar essa dominação de maneira amigável e com consentimento dos habitantes Navis, e resolvem então invadir o planeta, massacrando a população com armas de fogo e maquinários bélicos potentes. Dra. Grace revolta-se e então decide lutar ao lado dos nativos, defendendo o planeta e seus habitantes.

A categoria que retrata o cientista como um indivíduo diabólico foi encontrada em quatro dos filmes analisados: FIC02, FIC05, FIC10 e FIC14. Essa categoria revela cientistas que prioritariamente possuem objetivos de reverter os limites humanos, ultrapassando e/ou alterando o que seria considerado como atribuições ou criações divinas. Sendo assim, possuem criações ou invenções polêmicas que afetam diretamente a sociedade e seus integrantes.

Em FIC10, Dr. Merrick é o cientista responsável pela coordenação e manutenção da ordem nos setores demonstrados no filme. O filme possui um teor altamente tecnológico e cientifico, desde a ideia principal de produção de clones a pedido de seres humanos com algum desejo ou demanda específica. A manipulação desses clones e sua manutenção de 
forma saudável e ativa, assim como a concepção desse local que viabiliza essa estrutura, são atribuídas ao Dr. Merrick, que comanda o local.

Dr. Merrick acompanha individualmente cada clone, realizando consultas individuais que se assemelham a breves consultas médicas com pitadas de sessões de terapia. Em uma cena com o clone Lincoln Seis-Eco, ele pergunta sobre como ele está se sentindo e diante de uma série de questionamentos apresentados pelo clone, o cientista o leva para outro aposento, realizando um procedimento bem singular, liberando sob a pele do indivíduo microsensores que se locomovem como insetos, introduzindo-se nos olhos de Lincoln SeisEco. Nessa cena, características do personagem Dr. Merrick, como a frieza e até mesmo a crueldade diante de Lincoln Seis-Eco, ficam evidentes. Percebemos esses traços com o diálogo abaixo.

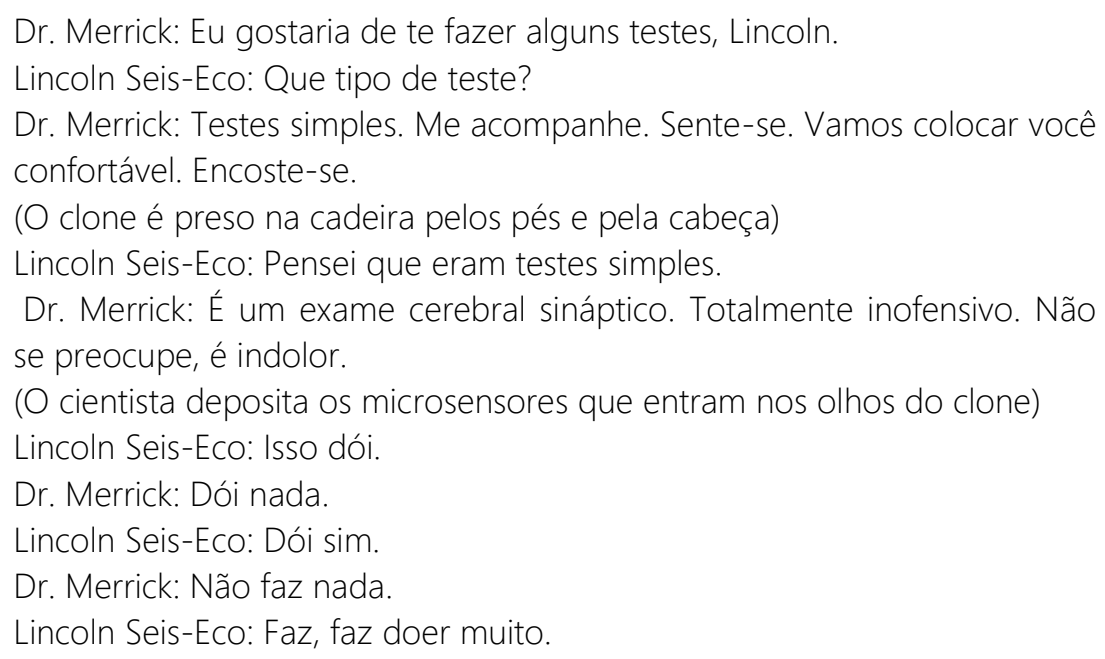

Neste trecho do diálogo percebe-se a intenção de controle e manipulação do cientista em relação a Lincoln Seis-Eco. Os objetivos e as atitudes do médico cientista se revelam duvidosos a todo momento. A postura do cientista é discutida por Lincoln Seis-Eco com o personagem Mac, seu amigo, como observamos no diálogo.

\footnotetext{
Lincoln Seis-Eco: O que se passa com o Dr. Merrick?

Mac: Você quer dizer, por que ele age como se tivesse o rei na barriga? Lincoln Seis-Eco: (ri cuspindo e confirma)

Mac: É o chamado complexo de Deus. Os médicos são todos assim. Pensam que sabem tudo.
}

Observa-se na fala do personagem Mac uma representação negativa do cientista, insinuando que todos os médicos são arrogantes. Dessa forma, essa imagem de cientista se associa à personalidade negativa de Dr. Merrick demonstrada no filme. Essa representação de cientista pode influenciar os espectadores a formar uma imagem de desconfiança em relação aos médicos, que serão vistos como presunçosos.

Barca (2005) discute que, desde os primórdios das produções cinematográficas, a imagem dos cientistas é atrelada ao gênero de terror, onde as descobertas científicas estão associadas a ameaças à humanidade. A autora afirma que, em um primeiro movimento cinematográfico, os cientistas eram representados por indivíduos esquisitos, que viviam em determinada região isolada, como é retratado nos filmes 0 médico e o monstro e Frankenstein, ambos lançados na década de 1930. 
Assim, percebe-se que, por diversas vezes, o cinema representa o cientista de maneira negativa, expondo um lado ambicioso e lunático, em que as aspirações e objetivos desses indivíduos apresentam um imenso potencial de prejudicar até mais do que beneficiar a sociedade. Essa visão de cientista permite observar uma fragilidade humana no mesmo, o que desconfigura o perfil ilibado do estereótipo confiável e sábio de cientista do senso comum. A possibilidade da existência de um indivíduo que exerce ciência e possua um caráter duvidoso e até mesmo notoriamente corrompido, admite uma incerteza diante do direcionamento dado à ciência, podendo assumir um caminho desfavorável para a sociedade (QUEIROZ, 2019).

Outro caso que indica esse perfil de cientista é visto no filme Wolverine, onde a personagem Dra. Green, inicialmente uma respeitada cientista, revela-se como uma inescrupulosa vilã mal intencionada em relação ao personagem principal Wolverine. Essa personagem tem uma importância dupla, pois além de trazer essa ambiguidade dos interesses envolvidos na ciência e da possibilidade de haver cientistas com esse perfil, ainda atribui esse parâmetro a uma personagem feminina, o que também desconstrói diversas características femininas.

Quando é apresentada pelo senhor Yashida como sua oncologista, aparece com uma imagem de cientista tradicional, utilizando jaleco e óculos, aparentando a credibilidade relativa ao estereótipo científico, o que causa uma boa impressão inclusive em Wolverine, que a elogia para o amigo. A desconstrução da personagem e a revelação de sua personalidade maléfica, assim como do uso da ciência realizado por ela para fins nocivos, somente são desvendados ao longo da trama.

No meio do filme, Wolverine passa a desconfiar da Dra. Green, quando indaga sobre ela à neta de seu amigo, afirmando que a médica fez algo que removeu sua capacidade de regeneração, que não estava como antes diante dos ferimentos que adquiriu em batalha. Na cena seguinte, Dra. Green já aparece produzida de uma maneira diferente, com os cabelos soltos e vestimenta sensual, e encontra-se com Harada, cobrando a ele a tarefa de entregar-Ihe Logan, confirmando que ela removeu seus poderes no intuito de facilitar sua captura. Após essa afirmação, intimida Harada, exigindo o respeito do mesmo devido à ameaça e risco que sofre diante de seu poder. Desse modo, fica claro com seu comportamento agressivo e ambicioso, a intenção de fazer mal ao personagem principal. Sua postura fria, calculista e cruel lhe enquadra como uma cientista diabólica, que manipula os recursos da ciência médica para prejudicar Logan e alcançar benefício próprio.

A seguir, percebemos um momento em que Dra. Green, assumindo sua postura de Madame Hidra/Víbora, ao invadir a casa de Yashida:

Shingen Yashida: O que é você?

Dra. Green: Uma química, uma niilista, uma capitalista, uma mutação. Uma víbora.

(Lambe a ponta de uma caneta com uma língua de cobra, depositando na mesma veneno, e depois de sua fala enfiando a mesma no pescoço do outro personagem, fazendo com que o mesmo urre de dor e saia cambaleante. Dra. Green deixa o aposento sorrindo.)

Em um diálogo seguinte com Logan, preso em um laboratório, Dra. Green discorre:

Fui contratada pela minha discrição. Isso é um certo talento para combinar bioquímica e metafísica. Toxinas fortes são minha especialidade. 
Claro que ajuda ser geneticamente imune a todos os venenos conhecidos pela humanidade como eu sou. E imune à toxina que é o próprio homem como eu também sou.

Essas definições alegadas pela própria personagem determinam sua personalidade vil e a motivação de utilizar a ciência para fins que não incluem benefício algum, sobretudo à humanidade. Contrapondo essa visão de cientista, Colagrande e Arroio (2018) em um estudo com licenciandos concluintes do curso de Química investigaram as representações sobre ciência e cientista. Em seus resultados, os autores constataram uma percepção de cientista contendo diversos predicados positivos, como o cientista sendo um sujeito estudioso, dedicado, curioso e determinado, buscando respostas que possam contribuir para o benefício da sociedade.

Essa visão deve ser relativizada a partir de uma abordagem mais humana da ciência, admitindo a possibilidade do cientista ser um indivíduo que pode ter intenções negativas e egoísticas no desenvolvimento de suas pesquisas. Filmes como os pertencentes a essa categoria podem ser um ponto de partida para questionar essas características vinculadas à imagem do cientista.

No que diz respeito a categoria Cientista professor, destacamos que foi analisada a representação dos cientistas exercendo essa postura de professor, não exatamente ocupando um cargo docente, mas sim, um sujeito que apresenta grande conteúdo e conhecimento sobre o tópico científico que é abordado no filme e se posiciona dessa forma. De acordo com a categoria proposta por Oliveira (2006), o cientista professor é bem intencionado em suas pesquisas e descobertas, contudo apresenta uma ingenuidade que geralmente culmina no fato de sua pesquisa sair de seu controle durante a aplicação e acaba se direcionando de maneira inesperada.

Observamos a ocorrência dessa representação de cientista em três filmes analisados, sendo eles A Experiência, Blade Runner e Efeito Borboleta. Nesses filmes, os personagens são os responsáveis pela idealização, elaboração e acompanhamento das pesquisas científicas.

No caso de Blade Runner, o cientista Eldon Tyrell aparece como o criador dos androides "replicantes", que surgem para atender aos desejos e necessidades humanas, porém acabam desenvolvendo suas próprias emoções, o que faz com que a pesquisa fuja do controle do pesquisador, ocasionando a expulsão dos indivíduos da Terra. O personagem apresenta um porte culto e elegante, condizente com o estereótipo esperado e projetado para os intelectuais e, em todas as cenas em que aparece aparenta seriedade e autocontrole dos indivíduos em que a racionalidade prevalece.

No diálogo com o "replicante" que porventura irá matá-lo, é estabelecida uma referência paterna com o mesmo e, em seu discurso, o cientista se posiciona de forma fraterna e condescendente, conforme percebemos abaixo:

Dr. Tyrell: Qual parece ser o problema?

Replicante: A morte.

Dr. Tyrell: A morte? Receio que esteja um pouco fora do meu alcance.

Replicante: Eu quero mais vida, pai!

Dr. Tyrell: Os fatos da vida...Provocar uma alteração na evolução do sistema vital orgânico é fatal. A sequência de código não pode ser alterada, uma vez estabelecida.

Replicante: Por que não? 
Dr. Tyrell: Porque ao segundo dia de incubação, as células sujeitas a mutações regressivas dão origem a colônias de regressores. Como ratos num navio. E o navio afunda.

Dr. Tyrell: A luz que brilha com o dobro da intensidade, brilha metade do tempo. E você brilhou tão intensamente, Roy. Olhe bem pra você. Você é o filho pródigo. Um prêmio e tanto.

Replicante: Eu fiz coisas questionáveis.

Dr. Tyrell: E coisas extraordinárias. Gozou bem da sua vida.

Replicante: Nada que o Deus da biomecânica não permitisse entrar no Paraíso.

O replicante Roy, ávido por mais tempo de vida, procura o cientista na expectativa de que o mesmo possa concretizar seu desejo de durar mais tempo. Contudo, ao perceber a coerência dos argumentos e explicações do cientista, e apesar de sua postura gentil e fraterna, o replicante assassina seu criador.

Podemos observar no diálogo essa representação de um cientista pleno do domínio de seu conhecimento, onde prontamente já consegue responder às dúvidas e anseios apresentadas pelo seu "aluno" e criação. E exatamente como o exposto por Oliveira (2006) na proposta da categoria, o cientista professor têm seu trabalho fugindo de seu controle, uma vez que o mesmo não poderia imaginar e certamente não planejou que isso acontecesse, que sua criação iria matá-lo naquele momento. Mas, durante a cena, o cientista demonstra muito apreço pela criação, reconhecendo seu valor e mérito pelos feitos realizados em sua vida, revelando inclusive um orgulho por ele, realmente como um pai faria.

Segundo Rosa et al. (2005), essa caracterização de pai atribuída ao cientista e o vínculo afetivo com a sua criatura estabelece a criação de uma cientista humanizado, como ocorre em determinados casos de desenhos infantis citados no trabalho como As Meninas Superpoderosas e Poochini. Dentro desse princípio, o cientista é retratado como um indivíduo sensível, que projeta em seu trabalho científico um grande afeto, que muitas vezes compensa suas próprias frustrações e falhas humanas.

Esse perfil de cientista professor também pode relacionar-se com um traço de personalidade que aparece de forma recorrente na literatura atribuído ao cientista, o fato do mesmo ser extremamente estudioso, intelectual e interessado na investigação de questões científicas de maneira exaustiva e dedicada (QUEIROZ, 2019).

Galvão e Reis (2008) afirmam que essa exigência de dedicação estipulada pelo estereótipo de cientista do senso comum, muitas vezes afasta certas pessoas de cogitarem ingressar em uma carreira científica, sobretudo as crianças que creem não ter condições e capacidade de se dedicarem tanto à ciência. Reznik et al. (2017) reiteram ainda, através dos resultados de seu estudo, que adolescentes acreditam que, como requisitos para tornar-se cientista, é preciso ter inteligência acima da média, ser criativo, inventivo, fazer experimentos e questionamentos e observar fórmulas e teorias. Todas essas determinações tornam o exercício da ciência distante para muitos jovens.

O discurso eloquente, técnico e explicativo também é um traço encontrado em personagens que se enquadram nessa categoria. No filme A Experiência, por exemplo, o mentor da pesquisa, mesmo se direcionando a especialistas, em um momento inicial do filme, expõe o contexto e a situação enfrentada com diversos termos e conteúdos específicos da ciência, sobretudo da genética. Durante seu discurso, o personagem cientista 
Dr. Xavier Fitch assume uma postura didática, onde sua explanação passa aos outros personagens o conhecimento do que ocorreu e foi realizado até o momento. Dessa forma, os demais podem ficar cientes das características dos acontecimentos e compreender o contexto e a situação para saber o que é necessário no cenário vigente.

Essa função expositiva do discurso, adotada pelo personagem, demonstra seu perfil e pertencimento à categoria de cientista professor. Mais uma vez em FIC05, se reafirma uma imagem de cientista soberano, detentor dos conhecimentos científicos vigentes e que teve suas pesquisas, apesar de bem intencionadas, tomando um rumo inesperado e arriscado.

Segundo Santos (2018), a credibilidade atribuída ao discurso de um cientista é um dos aspectos mais importantes para a confiabilidade da ciência e de seus respectivos resultados. O reconhecimento do trabalho desenvolvido depende dessa credibilidade, assim como a possibilidade de levantamento das hipóteses associadas à pesquisa ou a novas propostas também dependerá desse discurso. Outro ponto defendido pela autora é a comunicação dos dados obtidos, não só entre os pares mas também para a população.

Por fim, o último filme que traz um cientista que se enquadra na categoria cientista professor é Efeito Borboleta. No filme, o psiquiatra Dr. Redfield apresenta-se com bastante seriedade e formalidade em sua atuação profissional. Nos momentos em que manifesta suas opiniões médicas, é sempre incisivo e contundente, determinando com bastante segurança o que afirma. Essa maneira categórica de colocar o conhecimento científico, expressado de forma unilateral, onde os familiares e pacientes somente recebem aquelas informações sem possibilidade de contestação, classifica o personagem na categoria de cientista professor (QUEIROZ, 2019).

Apesar de seu posicionamento muitas vezes heroico, os personagens pertencentes a categoria do Cientista idealista apresentam um idealismo maior, de realmente serem capazes de intervir ao ponto de salvar a humanidade através de seus feitos. Assim, lutam para reverter alguma catástrofe iminente ou almejam a construção de determinada sociedade utópica, onde, de alguma maneira, sua atividade científica poderá beneficiar diretamente toda a população.

Em O Dia Depois de Amanhã, o cientista passa por um episódio de alto risco, onde quase despenca em uma cratera no meio de uma geleira, enquanto estava em campo realizando suas pesquisas. Após constatar que havia uma mudança climática acentuada, retorna à cidade de origem e faz uma declaração à imprensa, colocando a população a par do que estava ocorrendo no planeta. O discurso do Dr. Jack Hall no evento Conferência Mundial sobre aquecimento global promovido pela $\mathrm{ONU}$, demonstra sua profunda preocupação com a situação do planeta e as consequências geradas para a humanidade. Observa-se um interesse pela coletividade a partir de seu posicionamento, onde defende que medidas e soluções devem ser tomadas para evitar maiores catástrofes. Realiza explicações baseadas em fundamentações e exemplos que indicam a gravidade do que foi descoberto em sua pesquisa.

Revela a um público selecionado, composto por líderes e governantes mundiais, as condições e as perspectivas globais aos quais o clima pode afetar. Dessa forma, assume uma responsabilidade de mensageiro de um cenário catastrófico iminente e busca um pensamento crítico por parte de seu público, que possui meios para reverter ou ao menos interromper o que está para acontecer. Direcionando assim, e apresentando essas características, Dr. Jack Hall se encaixa no perfil da categoria de cientista idealista. 
Kirby (2003) aponta que a imagem dos cientistas nos filmes pode servir para promover determinadas ideias ou conceitos. Desse modo, um cientista idealista representa toda uma conjuntura referente ao tema de estudo ao qual o mesmo se dedica e é despontado no filme. Quanto ao aquecimento global, tópico explorado em O Dia Depois de Amanhã, é uma questão urgente e contemporânea, de proporções mundiais, que merece atenção e cuidado por parte dos governantes, assim como da população, que precisa despertar seu olhar para as mudanças climáticas e sua relação com as ações antrópicas cotidianas.

Quanto à imagem de um cientista idealista no cinema, Levin e Kreimer (2018) afirmam que é um dos perfis mais recorrentes a serem encontrados para representar os cientistas. Sobre as características desse tipo de cientista, os autores descrevem ainda que são sujeitos que creem poder modificar o mundo sozinhos, até mesmo realizando experimentos em seu próprio corpo, levando esse idealismo beirar a uma certa estupidez.

Uma veiculação idealista da ciência, para Neto (2017), contribui para a distorção da visão da ciência que, geralmente, encontra-se atrelada ao pensamento de que a mesma é neutra. $\bigcirc$ autor ressalta que esse conceito idealista classifica a ciência como atividade exclusivamente benéfica, detentora de todas as soluções para a sociedade, um discurso que é reforçado também pela escola e por outros meios de divulgação científica como jornais, televisão e revistas.

A postura idealista também é identificada no cientista Adrian no filme 2012, ao constatar a maior erupção solar da história em sua visita a uma mina de cobre com 2100 metros de profundidade no Instituto de Astrofísica na Índia. A erupção ocasionou a multiplicação dos neutrinos, que começam a causar uma reação física, gerando um aquecimento do centro da Terra em um efeito semelhante a um micro-ondas. Diante da descoberta, Dr. Adrian adentra um evento de gala no meio da noite em Washington para informar às autoridades sobre o risco sofrido pela humanidade. A urgência e a impetuosidade do cientista em se impor para relatar a importância da descoberta e a gravidade de seus possíveis efeitos denota seu idealismo.

Dr. Adrian insiste ao ponto de garantir que a autoridade representada pelo Sr. Anheuser levasse a sério os dados que trazia e prestasse atenção nos mesmos. $O$ bem comum torna-se prioridade nesse momento e o cientista enfrenta a situação de desdém e humilhação a que estava sendo submetido, a fim de que a informação fosse passada. A crença de que a partir de sua expertise e da ação emergencial o processo catastrófico possa ser interrompido era o que importava para o cientista naquele momento. Assim, o cientista revela-se como um idealista que acredita que através da ciência é possível salvar a humanidade, criando soluções para cenários desfavoráveis.

Por fim, a categoria de cientista inventor é a que mais se aproxima do estereótipo encontrado na visão popular sobre o cientista. Entretanto destacamos que em nosso estudo foi a que apresentou menor recorrência. Esta categoria reúne mais atributos da imagem estereotipada, que determina que o cientista é um indivíduo genial, que trabalha sozinho, capaz de realizar descobertas fantásticas em seu laboratório, que geralmente é antissocial, apresentando certos distúrbios emocionais e psicológicos, sendo um sujeito desequilibrado (TOMAZI et al., 2009).

O filme que apresenta um personagem que possui essas características e portanto se enquadra nessa categoria é apenas o filme De Volta Para o Futuro. O Doutor Emmett Brown é retratado como um indivíduo obcecado por sua obra científica, busca de maneira incessante desenvolver um dispositivo capaz de transitar no tempo e acaba conseguindo 
produzi-lo em um De Lorean, criando um carro que é uma máquina do tempo capaz de regressar ao passado.

Dr. Brown demonstra seu afinco, assim como sua genialidade, em algumas cenas retratadas no filme, onde discorre sobre seus cálculos e estimativas para a realização das experiências de viagem no tempo almejadas. Inicialmente envia o cão Einstein e posteriormente decide enviar seu amigo e assistente Martin McFly. O cientista apresenta uma personalidade pouco convencional e entusiasmo diante de suas façanhas, a começar pelo horário em que marca um encontro, as 1 h16 da madrugada, com seu assistente em um estacionamento de shopping center. No início da cena, aparece o caminhão do cientista estacionado, onde está escrito "Empresas Dr. E. Brown - 24 horas de serviços científicos", dando a entender que a dedicação requerida para o cargo científico exigiria um período integral.

Além disso, em algumas cenas do filme percebe-se uma mistura da genialidade de Dr. Brown, sendo capaz de realizar uma conquista científica jamais alcançada pela humanidade e ao mesmo tempo determinados traços de fragilidade que humanizam o personagem. Essa personalidade mais irreverente faz parte de um movimento, segundo Barca (2005), que ocorre na representação dos cientistas a partir da década de 1980. O autor afirma que o cinema passa, na segunda metade dessa década, a retratar os cientistas como sujeitos atrapalhados e geniais, realizando experiências divertidas, inovadoras e arriscadas.

Essa combinação foi favorável para o cinema, visto que o primeiro filme da trilogia de De Volta Para o Futuro representa uma das maiores bilheterias de comédia da história do cinema. Infere-se assim, que possa influenciar no processo de construção do pensamento científico popular, uma vez que esse perfil de cientista conquistou a simpatia do público.

A imagem do Dr. Brown é compatível com a visão de cientista de muitos indivíduos, inclusive estudantes do ensino médio. Soares e Scalfi (2014), em seu estudo, atestaram que a maioria dos alunos representava através de desenhos o cientista com características semelhantes ao personagem de De Volta Para o Futuro. Inclusive três alunos desenharam precisamente Einstein, uma figura emblemática da ciência, que possui traços similares com o Dr. Brown, a começar pelos cabelos brancos compridos e despenteados.

Galvão e Reis (2008) também investigaram as representações de estudantes sobre ciência e cientistas e observaram que a maioria dos alunos percebem o cientista com a característica da loucura e excentricidade, corroborando com o perfil do personagem de Dr. Emmett Brown.

O filme, dessa forma, reforça a imagem de cientista presente no imaginário popular e reproduz certos conceitos relacionados à prática científica que não condizem com a realidade. Sugere-se assim, que este filme, da década de 80, possa servir para discutir a representação do cientista em comparação com outros filmes, assim como identificar e perceber possíveis mudanças ao longo dos anos.

\section{Considerações finais}

Com este estudo foi possível perceber que nos filmes de ficção cientifica predomina a representação do cientista como um indivíduo herói-aventureiro, capaz de realizar feitos incriveis em prol de sua pesquisa e da humanidade. As representações identificadas nos 14 filmes de ficção cientifica analisados revelaram-se bastante interessantes no sentido de gerar 
reflexões críticas sobre o papel do cientista e de outros direcionamentos realizados no âmbito científico.

Como desdobramentos para futuras pesquisas, podemos sinalizar a relevância de investigar possíveis motivações para as diferentes representações de cientista nos filmes de ficção científica. Além disso, pode-se pensar acerca dos impactos nas representações de cientista por professores e estudantes após a exibição e observação crítica desse conjunto heterogêneo de filmes.

Dessa forma, destaca-se a relevância de mais estudos voltados para a análise de filmes comerciais, observando como a ciência vem sendo retratada. Assim, será possível perceber o filme como fonte de conhecimento científico e também como recurso para questionar e mobilizar representações permeadas em seus discursos. Importante salientar que tais representações devem ser identificadas e problematizadas, enquanto materiais com potencial para suscitar discussões nos mais variados contextos sociais, inclusive no âmbito escolar.

\section{Referências}

ALBUQUERQUE, E. A. de F. Ciências em cena: o cinema como registro histórico-filosófico das visões dos educandos sobre as ciências da natureza. Revista Ciências e Ideias, v. 7, n. 3, p. 149-166, 2017.

BARCA, L. As múltiplas imagens do cientista no cinema. Comunicação e Educação, v. 10, n. 1, p. 31-39, 2005.

BARDIN, L. Análise de conteúdo. São Paulo: Edições 70, 2011.

BREUNIG, E.T.; AMARAL, A.S.; GOLDSCHIMIDT, A. I. História da Ciência: revelando concepções fragmentadas a partir de imagens de cientistas. Amazônia Revista de Educação em Ciências e Matemática, v.15, n.3, p.134-150, 2019.

COLAGRANDE, E.A.; ARROIO, A. Representações sociais sobre ciência e cientistaimportante discussão na formação de professores de química. Educação Química en Punto de Vista, v. 2, n. 1, p. 12-28, 2018.

FIORESI, C.A.; CUNHA, M.B. Mafalda e a divulgação da ciência. Revista Educação e Cultura Contemporânea, v. 14, n. 34, p. 162-176, 2016.

GALVÃO, C.; REIS, P. A promoção do interesse e da relevância do ensino da ciência através da discussão de controvérsias sociocientíficas. Ciência-tecnologia-sociedade no ensino das ciências: Educação científica e desenvolvimento sustentável, p. 131-135, 2008.

KIRBY, D. A. Scientists on the set: Science consultants and the communication of science in visual fiction. Public Understanding of Science, v. 12, n. 3, p. 261-278, 2003.

KOSMINSKY, L.; GIORDAN, M. Visões de Ciências e Sobre Cientistas entre Estudantes de Ensino Médio. Revista Química Nova na Escola, n.15, p.11-18, 2002.

LATOUR, B. Experimentos em arte e política. Revista do Programa de Pós-Graduação em comunicação social da faculdade de comunicação e artes, v. 1, p.17-27, 2012. 
LEVIN, L.; KREIMER, P. A ciência no cinema: dimensões sociais e culturais.

Disponível em: https://www.academia.edu/8996576/A_ci\%C3\%AAncia_no_cinema_dimens\% C3\%B5es_sociais_e_culturais. Acesso em: dezembro, 2018.

NETO, A. No 'Show da vida' há um (im)possível para a ciência?: os efeitos de sentidos sobre o discurso jornalístico do Fantástico. Dissertação (Mestrado em Comunicação Social), UNICAMP, Campinas, 2017, 132f.

OLIVEIRA, B.J. Cinema e imaginário científico. História, ciências, saúde-manguinhos, v. 13, 2006.

QUEIROZ, A.P.B. Análise das representações sobre Natureza da Ciência em filmes de ficção científica. Tese (Doutorado em Ciência, Tecnologia e Educação). Programa de Pósgraduação em Ciência, Tecnologia e Educação. Centro Federal de Educação Tecnológica Celso Suckow da Fonseca, Rio de Janeiro, 2019, $254 \mathrm{f}$.

REZNIK, G.; MASSARANI, L.M.; RAMALHO, M.; MALCHER, M.A.; AMORIM, L.; CASTELFRANCHI, Y. Como adolescentes apreendem a ciência e a profissão de cientista? Estudos Feministas, v. 25, n. 2, p. 829-855, 2017.

ROSA, M I.P.; LUDWIG, B.E.; WIRTH, I.G.; FRANCO, P.C.; DUARTE, T.F. Os cientistas nos desenhos animados e os olhares das crianças. Atas... IV Encontro Nacional de Pesquisa em Ensino de Ciências, Bauru, São Paulo, 2005.

SANTOS, B. S. Um discurso sobre as ciências. Cortez Editora, 2018.

SANTOS, E.G..; SCHEID, N.M.J. A história da Ciência no cinema: contribuições para a problematização da concepção de Natureza da Ciência. Atas... VIII Enpec-Encontro de Pesquisa em Educação em Ciências, Santo Ângelo-RS, 2011.

SANTOS, E.G..; PASINI, M.; RUDEK, K. Reflexões sobre o uso da mídia cinematográfica no Ensino de Ciências e Biologia nos ENEBIO. Anais... X Encontro Nacional de Pesquisa em Educação em Ciências, Águas de Lindóia, São Paulo, 2015.

SCHEID, N. M. J.; FERRARI, N.; DELIZOICOV, D. Concepções sobre a natureza da ciência num curso de ciências biológicas: imagens que dificultam a educação científica. Investigações em Ensino de Ciências, v. 12, n. 2, p. 157-181, 2016.

SILVA, C.; CHRISTO GOBBI, B.; ADALGISA SIMÃO, A. O uso da análise de conteúdo como uma ferramenta para a pesquisa qualitativa: descrição e aplicação do método. Organizações rurais e agroindustriais, v. 7, n. 1, p. 23-40, 2005.

SOARES, G.; SCALFI, G.. Adolescentes e o imaginário sobre cientistas: análise do teste "Desenhe um cientista"(DAST) aplicado com alunos do $2^{\circ}$ ano do Ensino Médio.

In: Congreso Iberoamericano de Ciencia, Tecnología, Innovación y Educación. Buenos Aires, Argentina, 2014.

TOMAZI, A.L.; PEREIRA, A.J.; SCHULER, C.M.; PISKE, K.; TOMIO, D. O que é e quem faz ciência? Imagens sobre a atividade científica divulgadas em filmes de animação infantil. Ensaio Pesquisa em Educação em Ciências, v. 11, n. 2, p.335-353, 2009. VANOYE, F.; GOLIOT-LÉTÉ, A. Introduzione all'analisi del film. Lindau, 2006. 